\title{
Structural variations of uranium compounds with nitrate anions
}

Anastasiya Igorevna Zadoya ${ }^{1}$, Oleg I. Siidra ${ }^{1}$, Evgeniy V. Nazarchuk ${ }^{1}$

${ }^{1}$ Saint Petersburg State University, Department Of Crystallography, Saint Petersburg, Russian Federation E-mail: izanastasiia@gmail.com

The nitrate anion, NO 3 - , is known to be widely used in different stages of the PUREX (Plutonium and Uranium Recovery by Extraction) process [1]. By changing nitrate concentration of the initial solution, one may control separation of actinides by various procedures. Three major coordination environments by ligands are observed for linear (UO 2 ) 2+ uranyl (Ur) ion in oxocompounds. It is typically coordinated by four, five or six ligands, arranged at the equatorial vertices of UrO 4 (square), UrO 5 (pentagonal bipyramid) or UrO 6 (hexagonal bipyramid), respectively. Nitrate groups in inorganic uranium compounds may either directly coordinate uranyl ion thus forming [( UO 2 )(NO 3 ) n X m ] or being bonded to interstitial cations only with formation of [(UO 2 )X m ](NO 3 ) n complexes, where $\mathrm{X}=\mathrm{O}, \mathrm{Cl}, \mathrm{Br}$. Four new uranyl-nitrate compounds were obtained from aqueous solutions: ( $\mathrm{CH} 3$ ) 2 ( $\mathrm{NH} 2$ ) 2 [(UO 2 ) 2 ( NO 3 ) 2 (CrO 4 ) 2 (H 2 O)]H 2 O (1), (15-crown- 5 ) 2 [(UO 2 ) 2 $(\mathrm{H} 2 \mathrm{O}) 4(\mathrm{O} 2$ )(NO 3 ) 2 ](H 2 O) 3.5 (2), Cs 2 [(UO) 2 (NO 3 ) $4(\mathrm{OH}) 2$ ] (3) and Rb 3 [(UO 2 )Cl 3 (NO 3 )](NO 3 ) (4). The structure of 1 is the first observation of one-dimensional unit (chain) with nitrate groups coordinating UrO 6 hexagonal pyramids and formation of $\left[\left(\mathrm{UO}_{2}\right) 2(\mathrm{NO} 3) 2(\mathrm{CrO} 4) 2(\mathrm{H} 2 \mathrm{O})\right]$. Compound 2 is a rare example of organically templated uranyl compound containing peroxide component with neutral organic and inorganic constituents. Neutral 15-crown- 5 and $\mathrm{H} 2 \mathrm{O}$ molecules are packed around [(UO2)2( $\mathrm{H} 2 \mathrm{O}) 4(\mathrm{O} 2)(\mathrm{NO} 3) 2]$ units providing structural stability exclusively via hydrogen and Van-der- Waals bonding. [(UO) 2 (NO 3 ) $4(\mathrm{OH}) 2$ ] clusters in the structure of 3 were not previously observed in inorganic compounds without organic molecules. And the structure of 4 contains both, NO3- directly coordinating uranyl and nitrate bonded to $\mathrm{Rb}$ atoms only. The latter is reflected in the structural formula of 4 .

This work was supported by the Saint-Petersburg State University internal grant 3.38.238.2015.

[1] Nash K.L. et al., J. Fuger (Eds.) (2006) Chemistry of the Actinide and Transactinide Elements, 4, Springer, The Netherlands, 2644-2666.

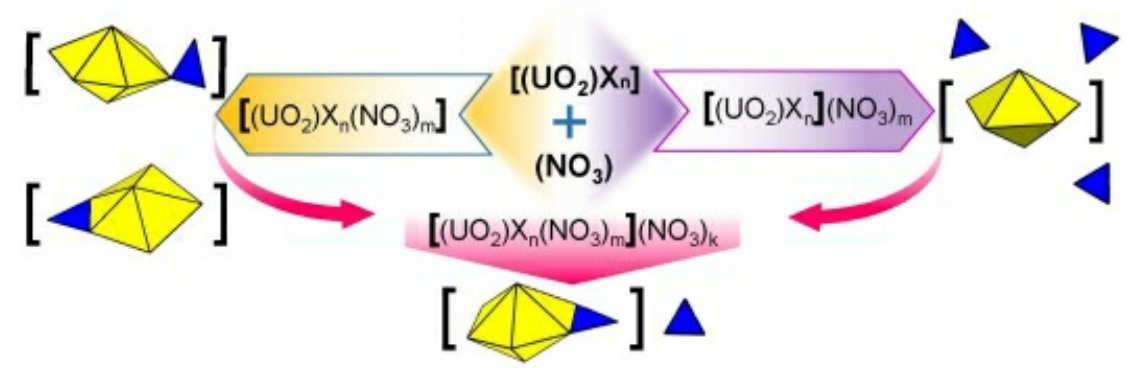

Keywords: nitrates, uranium, clusters 